PACS 31.15.A-;32.30.-r

O. L. Mykhailov, E. A. Efimova, E. V. Ternovsky, R. E. Serga

Odessa State Environmental University, L’vovskaya str.15, Odessa-9, 65016, Ukraine

E-mail: mykhailovo194@gmail.com

\title{
HYPERFINE STRUCTURE PARAMETERS FOR Li-LIKE MULTICHARGED IONS WITHIN RELATIVISTIC MANY-BODY PERTURBATION THEORY
}

\begin{abstract}
The relativistic many-body perturbation theory with the optimized Dirac-Kohn-Sham zeroth approximation is applied to calculation of the hyperfine structure parameters for some Li-like multicharged ions. The relativistic, exchange-correlation and other corrections are accurately taken into account. The optimized relativistic orbital basis set is generated in the optimal many-body perturbation theory approximation with fulfilment of the gauge invariance principle. The obtained data on the hyperfine structure parameters of the Li-like multicharged ions are analyzed and compared with alternative theoretical and experimental results.
\end{abstract}

\section{Introduction}

In last years a studying the spectra of heavy and superheavy elements atoms and ions is of a great interest for further development as atomic and nuclear theories (c.f.[1-12]). Theoretical methods used to calculate the spectroscopic characteristics of heavy and superheavy ions may be divided into three main groups: a) the multi-configuration Hartree-Fock method, in which relativistic effects are taken into account in the Pauli approximation, gives a rather rough approximation, which makes it possible to get only a qualitative idea on the spectra of heavy ions. b) The multi-configuration Dirac-Fock (MCDF) approximation (the Desclaux program, Dirac package) [1-4] is, within the last few years, the most reliable version of calculation for multielectron systems with a large nuclear charge; in these calculations one- and twoparticle relativistic effects are taken into account practically precisely.

The calculation program of Desclaux is compiled with proper account of the finiteness of the nucleus size; however, a detailed description of the method of their investigation of the role of the nucleus size is lacking.

In the region of small $\mathrm{Z}$ ( $\mathrm{Z}$ is a charge of the nucleus) the calculation error in the MCDF approximation is connected mainly with incomplete inclusion of the correlation and exchange effects which are only weakly dependent on $Z$; c) In the study of lower states for ions with $Z \leq 40$ an expansion into double series of the PT on the parameters $1 / \mathrm{Z}$, aZ (a is the fine structure constant) turned out to be quite useful. It permits evaluation of relative contributions of the different expansion terms: non-relativistic, relativistic, QED contributions as the functions of $\mathrm{Z}$.

Nevertheless, the serious problems in calculation of the heavy elements spectra are connected with developing new, high exact methods of account for the QED effects, in particular, the Lamb shift (LS), self-energy (SE) part of the Lamb shift, vacuum polarization (VP) contribution, correction on the nuclear finite size for superheavy elements and its account for different spectral properties of these systems, including calculating the energies and constants of the hyperfine structure, deriviatives of the one-electron characteristics on nuclear radius, nuclear electric quadrupole, magnetic dipole moments etc (c.f.[1-10]).

In this paper the relativistic many-body perturbation theory with the optimized DiracKohn-Sham zeroth approximation [11-19] is applied to calculation of the hyperfine structure parameters for Li-like multicharged ions. The relativistic, exchange-correlation and nuclear effects corrections are accurately taken into account with using the consistent and high precise procedures (c.g. [11-17]). 


\section{Relativistic many-body perturbation theory with optimized zeroth approximation and energy approach}

The theoretical basis of the RMBPT with the Dirac-Kohn-Sham zeroth approximation was widely discussed [11-17], and here we will only present the essential features. As usually, we use the charge distribution in atomic (ionic) nucleus $r(r)$ in the Gaussian approximation:

$$
\rho(r \mid R)=\left(4 \gamma^{3 / 2} / \sqrt{\pi}\right) \exp \left(-\gamma r^{2}\right)
$$

where $\gamma=4 / p R^{2}$ and $R$ is the effective nucleus radius. The Coulomb potential for the spherically symmetric density $r(r)$ is:

$$
V_{\text {nucl }}(r \mid R)=-\left((1 / r) \int_{0}^{r} d r^{\prime} r^{2} \rho\left(r^{\prime} \mid R\right)+\int_{r}^{\infty} d r^{\prime} r^{\prime} \rho\left(r^{\prime} \mid R\right)\right.
$$

Further consider the Dirac-like type equations for the radial functions $F$ and $G$ (components of the Dirac spinor) for a threeelectron system $1 s^{2} n l j$. Formally a potential $V(r \mid R)$ in these equations includes-electric and polarization potentials of the nucleus, $V_{X}$ is the exchange inter-electron interaction (in the zeroth approximation). The standard Kohn-Sham (KS) exchange potential is [13]:

$$
V_{X}^{K S}(r)=-(1 / \pi)\left[3 \pi^{2} \rho(r)\right]^{1 / 3} .
$$

In the local density approximation the relativistic potential is [33]:

$$
V_{X}[\rho(r), r]=\frac{\delta E_{X}[\rho(r)]}{\delta \rho(r)},
$$

where $E_{X}[\rho(r)]$ is the exchange energy of the multielectron system corresponding to the homogeneous density $\rho(r)$, which is obtained from a Hamiltonian having a transverse vector potential describing the photons. In this theory the exchange potential is $[3,4]$ :

$$
V_{X}[\rho(r), r]=V_{X}^{K S}(r) \cdot\left\{\frac{3}{2} \ln \frac{\left[\beta+\left(\beta^{2}+1\right)^{1 / 2}\right]}{\beta\left(\beta^{2}+1\right)^{1 / 2}}-\frac{1}{2}\right\},
$$

where $\beta=\left[3 \pi^{2} \rho(r)\right]^{1 / 3} / c, c$ is the velocity of light. The corresponding one-quasiparticle correlation potential

$$
V_{C}[\rho(r), r]=-0.0333 \cdot b \cdot \ln \left[1+18.3768 \cdot \rho(r)^{1 / 3}\right],
$$

(here $b$ is the optimization parameter; see below).

The perturbation operator contains the relativistic potential of the interelectron interaction of the form:

$$
V_{e-e}^{r e l}\left(r_{i}, r_{j}\right)=\frac{\left(1-\alpha_{i} \alpha_{j}\right)}{r_{i j}} \exp \left(i \omega_{i j} r_{i j}\right),
$$

(here $a_{i}, a_{j}$ are the Dirac matrices, $w_{i j}$ is the transition frequency) with the subsequent subtraction of the exchange and correlation potentials. The rest of the exchange and correlation effects is taken into account in the first two orders of the PT (c.g.[3-5].

In Refs. [20-29] it was presented the effective relativistic formalism with ab initio optimization principle for construction of the optimal relativistic orbital basis set. The minimization condition of the gauge dependent multielectron contribution of the lowest QED PT corrections to the radiation widths of the atomic levels is used. The alternative versions are proposed in refs. [30-37].

The general scheme of treatment of the spectra for Li-like ion is as follows. Consider the Dirac-type equations for a three-electron system $1 s^{2} n l j$. Formally they fall into one-electron Dirac equations for the orbitals $1 s 1 \mathrm{~s}$ and $n l j$ with the potential:

$$
V(r)=2 V(r \mid 1 s)+V(r \mid n l j)+V_{x}(r)+V(r \mid R)
$$

$V(r \mid R)$ includes the electrical and the polarization potentials of the nucleus; the components of the self-consistent Hartree-like potential, $V_{\mathbb{Q}}$ is the exchange inter-electron interaction (look below). The main exchange effect will be taken into account if in the equation for the $1 s$ orbital we assume

$$
V(r)=V(r \mid 1 s)+V(r \mid n l j)
$$

and in the equation for the $n l j$ orbital 


$$
V(r)=2 V(r \mid 1 s)
$$

The rest of the exchange and correlation effects will be taken into account in the first two orders of the PT by the total inter-electron interaction [13-17].

The used expression for $\rho(r \mid 1 s)$ coincides with the precise one for a one-electron relativistic atom with a point nucleus. The finiteness of the nucleus and the presence of the second $1 s$ electron are included effectively into the energy $E_{1 s}$.

Actually, for determination of the properties of the outer $n l j$ electron one iteration is sufficient. Refinement resulting from second iteration (by evaluations) does not exceed correlation corrections of the higher orders omitted in the present calculation.

The relativistic potential of core (the "screening" potential) $2 V^{(1)}(r \mid s)=V_{s c r}$ has correct asymptotic at zero and in the infinity. The procedures for accounting of the nuclear, radiative QED corrections are in details presented in Refs. [3-5, 14, 39-42].

\section{Results and Conclusions}

Energies of the quadruple $\left(W_{q}\right)$ and magnetic dipole $\left(W_{m}\right)$ interactions, which define a hyperfine structure, are calculated as follows [4]:

$$
\begin{gathered}
W_{q}=[D+C(C+1)] B, \\
W_{m}=0,5 A C, \\
D=-(4 / 3)(4 c-1)(I+1) /[i(I-1)(2 I-1)], \\
C=F(F+1)-J(J+1)-I(I+1) .
\end{gathered}
$$

Here $I$ is a spin of nucleus, $F$ is a full momentum of system, $J$ is a full electron momentum. Constants of the hyperfine splitting are expressed through the standard radial integrals:

$$
A=\left\{\left[(4,32587) 10^{-4} Z^{2} c g_{1}\right] /\left(4 c^{2}-1\right)\right\}(R A)_{-2},
$$

$$
B=\left\{7.287810^{-7} Z^{3} Q /\left[\left(4 c^{2}-1\right) I(I-1)\right\}(R A)_{-3},\right.
$$

Here $g_{I}$ is the Lande factor, $Q$ is a quadruple momentum of nucleus (in Barn); radial integrals are defined as follows:

$$
\begin{gathered}
(R A)_{-2}=\int_{0}^{\infty} d r r^{2} F(r) G(r) U\left(1 / r^{2}, R\right), \\
(R A)_{-3}=\int_{0}^{\infty} d r r^{2}\left[F^{2}(r)+G^{2}(r)\right] U\left(1 / r^{3}, R\right)
\end{gathered}
$$

and calculated in the Coulomb units $(=3,57$ $10^{20} Z^{2} \mathrm{~m}^{-2} ;=6,17410^{30} Z^{3} \mathrm{~m}^{-3}$ for valuables of the corresponding dimension). The radial parts $F$ and $G$ of two components of the Dirac function for electron, which moves in the potential $V(r, R)+U(r, R)$, are determined by solution of the Dirac equations (look above).

We have carried out the calculation of constants of the hyperfine interaction: the electric quadruple constant $B$, the magnetic dipole constant $\mathrm{A}$ with inclusion of nuclear finiteness and the Uehling potential for Li-like ions (c.g. [3-5]).

In table 4 the calculation results for the constants of the hyperfine splitting for the lowest excited states of Li-like ions are presented.

Analogous data for other states have been presented earlier (see ref. [5,20]). Our calculation showed also that a variation of the nuclear radius on several persents could lead to to changing the transition energies on dozens of thousands $10^{3} \mathrm{~cm}^{-1}$.

Table 1.

\section{Constants of the hyperfine electron-nuclear}

$$
\text { interaction: } A=Z^{3} \mathbf{g}_{I} \bar{A} \mathbf{c m}^{-1}, \quad B=\frac{Z^{3} Q}{\mathbf{c m}^{-1}} \bar{B}
$$

\begin{tabular}{|c|c|c|c|c|}
\hline$n l j$ & $Z$ & 69 & 79 & 92 \\
\hline $2 s$ & $\bar{A}$ & $176-02$ & $215-02$ & $\begin{array}{c}314 \\
-02\end{array}$ \\
\hline $3 s$ & $\bar{A}$ & $51-03$ & $63-03$ & $90-03$ \\
\hline $4 s$ & $\bar{A}$ & $19-03$ & $24-03$ & $36-03$ \\
\hline
\end{tabular}




\begin{tabular}{|c|c|c|c|c|}
\hline $2 p_{1 / 2}$ & $\bar{A}$ & $56-03$ & $71-03$ & $\begin{array}{l}105 \\
-02\end{array}$ \\
\hline $3 p_{1 / 2}$ & $\bar{A}$ & $16-03$ & $20-03$ & $31-03$ \\
\hline $4 p_{1 / 2}$ & $\bar{A}$ & $72-04$ & $91-04$ & $11-03$ \\
\hline \multirow[t]{2}{*}{$2 p_{3 / 2}$} & $\bar{A}$ & $67-04$ & $71-04$ & $72-04$ \\
\hline & $\bar{B}$ & $13-04$ & $15-04$ & $17-04$ \\
\hline \multirow[t]{2}{*}{$3 p_{3 / 2}$} & $\bar{A}$ & $19-04$ & $21-04$ & $22-04$ \\
\hline & $\bar{B}$ & $51-05$ & $55-05$ & $62-05$ \\
\hline \multirow[t]{2}{*}{$4 p_{3 / 2}$} & $\bar{A}$ & $89-05$ & $92-05$ & $8-04$ \\
\hline & $\bar{B}$ & $20-05$ & $22-05$ & $26-05$ \\
\hline \multirow[t]{2}{*}{$3 d_{3 / 2}$} & $\bar{A}$ & $10-04$ & $11-04$ & $12-04$ \\
\hline & $\bar{B}$ & $9-05$ & $10-05$ & $11-05$ \\
\hline \multirow[t]{2}{*}{$4 d_{3 / 2}$} & $\bar{A}$ & $51-05$ & $55-05$ & $58-05$ \\
\hline & $\bar{B}$ & $44-06$ & $50-06$ & $56-06$ \\
\hline \multirow[t]{2}{*}{$3 d_{5 / 2}$} & $\bar{A}$ & $48-05$ & $50-05$ & $52-05$ \\
\hline & $\bar{B}$ & $38-06$ & $39-06$ & $40-06$ \\
\hline \multirow[t]{2}{*}{$4 d_{5 / 2}$} & $\bar{A}$ & $19-05$ & $20-05$ & $21-05$ \\
\hline & $B$ & $15-06$ & $16-06$ & $17-06$ \\
\hline
\end{tabular}

\section{References}

1. Grant I. Relativistic Quantum Theory of Atoms and Molecules. Oxford, 2007.

2. Glushkov, A; Khetselius, O; Svinarenko, A; Buyadzhi, V. Spectroscopy of autoionization states of heavy atoms and multiply charged ions. Odessa: 2015.

3. Glushkov, A.V. Relativistic and correlation effects in spectra of atomic systems. Astroprint: Odessa, 2006.

4. Khetselius, O.Yu. Hyperfine structure of atomic spectra. Astroprint: Odessa, 2008.

5. Glushkov, A.V. Relativistic Quantum theory. Quantum mechanics of atomic systems.

Astroprint: Odessa, 2008.

6. Khetselius, O.Yu. Atomic parity non-conservation effect in heavy atoms and observing $\mathrm{P}$ and $\mathrm{PT}$ violation using NMR shift in a laser beam: To precise theory. J. Phys.: Conf. Ser. 2009, 194, 022009

7. Khetselius, O.Yu. Hyperfine structure of radium. Photoelectronics. 2005, 14, 83.

8. Khetselius, O.. Relativistic perturbation theory calculation of the hyperfine structure parameters for some heavy-element isotopes. Int. Journ. Quant. Chem. 2009, 109, 3330-3335.

9. Khetselius, O.Yu. Relativistic calculation of the hyperfine structure parameters for heavy elements and laser detection of the heavy isotopes. Phys.Scripta. 2009, 135, 014023.

10. Khetselius, O.Yu. Relativistic Hyperfine Structure Spectral Lines and Atomic Parity Non-conservation Effect in Heavy Atomic Systems within QED Theory. AIP Conf. Proc. 2010, 1290(1), 29-33.

11. Khetselius, O. Relativistic Calculating the Spectral Lines Hyperfine Structure Parameters for Heavy Ions. AIP Conf. Proc. 2008, 1058, 363-365.

12. Khetselius O.Yu.; Gurnitskaya, E.P. Sensing the hyperfine structure and nuclear quadrupole moment for radium. Sensor Electr. and Microsyst. Techn. 2006, 2, 25-29.

13. Khetselius, O.Yu.; Gurnitskaya, E.P. Sensing the electric and magnetic moments of a nucleus in the N-like ion of Bi. Sensor Electr. and Microsyst. Techn. 2006, 3, 35-39.

14. Khetselius, O.Yu. Quantum structure of electroweak interaction in heavy finite Fermi-systems. Astroprint: Odessa, 2011.

15. Svinarenko, A.A. Study of spectra for lanthanides atoms with relativistic many- body perturbation theory: Rydberg resonances. $J$. Phys.: Conf. Ser. 2014, 548, 012039.

16. Svinarenko, A.A. Study of spectra for lanthanides atoms with relativistic many- body perturbation theory: Rydberg resonances. $J$. Phys.: Conf. Ser. 2014, 548, 012039.

17. Svinarenko, A.A.; Ignatenko, A.V.; Ternovsky, V.B.; Nikola, L.V.; Seredenko, S.S.; Tkach, T.B. Advanced relativistic model potential approach to calculation of radiation 
transition parameters in spectra of multicharged ions. J. Phys.: Conf. Ser. 2014, 548, 012047.

18. Florko, T.A.; Tkach, T.B.; Ambrosov, S.V.; Svinarenko, A.A. Collisional shift of the heavy atoms hyperfine lines in an atmosphere of the inert gas. J. Phys.: Conf. Ser. 2012, 397, 012037.

19. Ivanova, E.P.; Ivanov, L.N.; Glushkov, A.V.; Kramida, A.E. High order corrections in the relativistic perturbation theory with the model zeroth approximation, $\mathrm{Mg}$-Like and Ne-Like Ions. Phys. Scripta 1985, 32, 513522.

20. Ivanov, L. N.; Ivanova, E. P.; Aglitsky, E. V. Modern Trends in the Spectroscopy of Multicharged Ions. Phys. Rep. 1988, 166, 315-390.

21. Glushkov, A.V.; Ivanov, L.N.; Ivanova, E.P. Autoionization Phenomena in Atoms. Moscow University Press, Moscow, 1986, 58160

22. Glushkov, A.V.; Ivanov, L.N. Radiation decay of atomic states: atomic residue polarization and gauge noninvariant contributions. Phys. Lett. A 1992, 170, 33-36.

23. Glushkov A.V.; Ivanov, L.N. DC strongfield Stark effect: consistent quantum-mechanical approach. J. Phys. B: At. Mol. Opt. Phys. 1993, 26, L379-386.

24. Glushkov, A.V. Spectroscopy of atom and nucleus in a strong laser field: Stark effect and multiphoton resonances. J. Phys.: Conf. Ser. 2014, 548, 012020

25. Glushkov, A.V. Spectroscopy of cooperative muon-gamma-nuclear processes: Energy and spectral parameters J. Phys.: Conf. Ser. 2012, 397, 012011

26. Glushkov, A.V. Advanced Relativistic Energy Approach to Radiative Decay Processes in Multielectron Atoms and Multicharged Ions. In Quantum Systems in Chemistry and Physics: Progress in Methods and Applications, Series: Progress in Theoretical Chemistry and Physics; Nishikawa, K., Maruani, J., Brandas, E., Delgado-Barrio, G., Piecuch, P., Eds.; Springer: Dordrecht, 2012; Vol. 26, pp 231-252.

27. Glushkov, A. Multiphoton spectroscopy of atoms and nuclei in a laser field: relativistic energy approach and radiation atomic lines moments method// Adv. Quant.Chem. (Elsevier), 2018, 78, doi.org/10.1016/ bs.aiq.2018.06.004

28. Khetselius, O.Yu. Relativistic Energy Approach to Cooperative Electron- $\gamma$-Nuclear Processes: NEET Effect In Quantum Systems in Chemistry and Physics, Series: Progress in Theoretical Chemistry and Physics; Nishikawa, K., Maruani, J., Brändas, E., Delgado-Barrio, G., Piecuch, P., Eds.; Springer: Dordrecht, 2012; Vol. 26, pp 217229.

29. Khetselius, O.Yu. Optimized Perturbation Theory for Calculating the Hyperfine Line Shift and Broadening of Heavy Atoms in a Buffer Gas. In Frontiers in Quantum Methods and Applications in Chemistry and Physics, Series: Progress in Theoretical Chemistry and Physics; Springer: Cham, 2015; Vol. 29, pp. 55-76.

30. Khetselius, O.Yu. Optimized relativistic many-body perturbation theory calculation of wavelengths and oscillator strengths for Li-like multicharged ions. Adv. Quant. Chem. 2019, 78, 223-251.

31. Khetselius, O.Yu. Quantum structure of electroweak interaction in heavy finite Fermi-systems. Astroprint: Odessa, 2011.

32. Svinarenko, A. A., Glushkov, A. V., Khetselius, O.Yu., Ternovsky,V.B., Dubrovskaya, Yu., Kuznetsova, A., Buyadzhi, V. Theoretical spectroscopy of rare-earth elements: spectra and autoionization resonances. Rare Earth Element, InTech. 2017, pp 83-104.

33. Glushkov, A.V., Khetselius, O.Yu., Svinarenko A.A., Buyadzhi, V.V., Ternovsky, V.B, Kuznetsova, A., Bashkarev, P Relativistic perturbation theory formalism to computing spectra and radiation characteristics: application to heavy element. Recent Studies in Perturbation Theory, ed. D. Uzunov (InTech) 2017, 131-150.

34. Glushkov A., Lovett L., Khetselius O., Gurnitskaya E., Dubrovskaya Y., Loboda A. Generalized multiconfiguration model of decay of multipole giant resonances applied to analysis of reaction (m-n) on the nucleus 
${ }^{40}$ Ca. Int. J. Mod. Phys. A. 2009, 24(2-3), 611-615

35. Glushkov, A.V.; Malinovskaya S.V. Co-operative laser nuclear processes: border lines effects In New Projects and New Lines of Research in Nuclear Physics. World Sci.: Singapore, 2003, 242-250.

36. Buyadzhi, V.V.; Chernyakova, Yu.G.; Smirnov, A.V.; Tkach, T.B. Electron-collisional spectroscopy of atoms and ions in plasma: Be-like ions. Photoelectronics. 2016, 25, 97-101.

37. Buyadzhi, V.V.; Chernyakova, Yu.G.; Antoshkina, O.; Tkach, T. Spectroscopy of multicharged ions in plasmas: Oscillator strengths of Be-like ion Fe. Photoelectronics. 2017, 26, 94-102.

38. Glushkov, A.V.; Ambrosov, S.V.; Ignatenko, A.V. Non-hydrogenic atoms and WannierMott excitons in a DC electric field: Photoionization, Stark effect, Resonances in ionization continuum and stochasticity. Photoelectronics, 2001, 10, 103-106.

39. Khetselius, O., Glushkov, A., Gurskaya M., Kuznetsova, A., Dubrovskaya, Yu.,
Serga I., Vitavetskaya, L. Computational modelling parity nonconservation and electroweak interaction effects in heavy atomic systems within the nuclear-relativistic many-body perturbation theory. J. Phys.: Conf. Ser. 2017, 905(1), 012029.

40. Glushkov, A.V.; Gurskaya, M.Yu.; Ignatenko, A.V.; Smirnov, A.V.; Serga, I.N.; Svinarenko, A.A.; Ternovsky, E.V. Computational code in atomic and nuclear quantum optics: Advanced computing multiphoton resonance parameters for atoms in a strong laser field. J. Phys.: Conf. Ser. 2017, 905, 012004.

41. Svinarenko A., Khetselius O., Buyadzhi V., Florko T., Zaichko P., Ponomarenko E. Spectroscopy of Rydberg atoms in a Blackbody radiation field: Relativistic theory of excitation and ionization. J. Phys.: Conf. Ser. 2014, 548, 012048.

42. Glushkov A.V., Khetselius O.Yu., Svinarenko A.A., Buyadzhi V.V., Methods of computational mathematics and mathematical physics. P.1. TES: Odessa, 2015 
O. L. Mykhailov, E. A. Efimova, E. V. Ternovsky, R. E. Serga

\title{
HYPERFINE STRUCTURE PARAMETERS FOR Li-LIKE MULTICHARGED IONS WITHIN RELATIVISTIC MANY-BODY PERTURBATION THEORY
}

Summary. The relativistic many-body perturbation theory with the optimized Dirac-Kohn-Sham zeroth approximation is applied to calculation of the hyperfine structure parameters for some Li-like multicharged ions. The relativistic, exchange-correlation and other corrections are accurately taken into account. The optimized relativistic orbital basis set is generated in the optimal many-body perturbation theory approximation with fulfilment of the gauge invariance principle. The obtained data on the hyperfine structure parameters of the Li-like multicharged ions are analyzed and compared with alternative theoretical and experimental results.

Keywords: Relativistic many-body perturbation theory - Optimal one-quasiparticle representation - Oscillator strengths -Energy approach - Correlation corrections

PACS 31.15.A-;32.30.-r

\author{
А. Михайлов, Э. А. Ефимова, Е. В. Терновский, Р. Э. Серга
}

\section{ПАРАМЕТРЫ СВЕРХТОНКОЙ СТРУКТУРЫ ДЛЯ Li-ПОДОБНЫХ МНОГОЗАРЯДНЫХ ИОНОВ В РАМКАХ РЕЛЯТИВИСТСКОЙ МНОГОЧАСТИЧНОЙ ТЕОРИИ ВОЗМУЩЕНИЙ}

Резюме. Релятивистская многочастичная теория возмущений с оптимизированным нулевым приближением Дирака-Кона-Шэма применена для расчета параметров сверхтонкой структуры Li-подобных многозарядных ионов. Релятивистские, обменно-корреляционные и другие поправки учитываются в рамках последовательных процедур. Оптимизированный базис релятивистских орбиталей генерируется в последовательном нулевом приближении релятивистской многочастичной теории возмущений, исходя из условия выполнения принципа калибровочной инвариантности. Полученные данные для параметров сверхтонкой структуры для Li-подобных многозарядных ионов анализируются и сравниваются с альтернативными теоретическими и экспериментальными результатами.

Ключевые слова: Релятивистская многочастичная теория возмущений., сверхтонкая структура, литий-подобные ионы

PACS 31.15.A-;32.30.-r

\author{
О. Л. Михайлов, Е. О. Ефімова, С. В. Терновський, Р. Е. Серга
}

\section{ПАРАМЕТРИ НАДТОНКОЇ СТРУКТУРИ ДЛЯ Lі-ПОДІБНИХ БАГАТОЗАРЯДНИХ ІОНІВ В РАМКАХ РЕЛЯТИВІСТСЬКОЇ БАГАТОЧАСТИНКОВОЇ ТЕОРІЇ ЗБУРЕНЬ}

Резюме. Релятивістська багаточастинкова теорія збурень з оптимізованим нульовим наближенням Дірака-Кона-Шема застосована для розрахунку параметрів надтонкої структури для Li-подібних багатозарядних іонів. Релятивістські, обмінно-кореляційні та інші поправки 
враховуються в рамках послідовних процедур. Оптимізований базис релятивістських орбіталей генерується в послідовному нульовому наближенні релятивістської багаточастинкової теорії збурень, виходячи з умови виконання принципу калібрувальної інваріантності. Отримані дані параметрів надтонкої структури для Li-подібних багатозарядних іонів порівнюються з альтернативними теоретичними і експериментальними результатами.

Ключові слова: Релятивістська багаточастинкова теорія збурень, надтонка структура, літій-подібні іони 